Check for updates

Cite this: RSC Adv., 2022, 12, 3801

\title{
Proton reduction by a bimetallic zinc selenolate electrocatalyst $\uparrow$
}

\author{
Aditya Upadhyay, (D) ${ }^{a}$ K. V. Saurav, (D) a Evelin Lilly Varghese, ${ }^{a}$ Ananda S. Hodage, ${ }^{a}$ \\ Amit Paul, (D) ${ }^{a}$ Mahendra Kumar Awasthi, ${ }^{b}$ Sanjay Kumar Singh (iD ${ }^{b}$ \\ and Sangit Kumar (iD *a
}

The development of alternative energy sources is the utmost priority of developing society. Unlike many prior homogeneous electrocatalysts that rely on a change in the oxidation state of the metal center and/ or electrochemically active ligand, here we report the synthesis and structural characterization of a bimetallic zinc selenolate complex consisting of a redox silent zinc metal ion and a tridentate ligand that catalyzes the reduction of protons into hydrogen gas electrochemically and displays one of the highest reported TOF for a homogeneous TM-metal free ligand centered HER catalyst, $509 \mathrm{~s}^{-1}$. The current-voltage analysis confirms the onset overpotential of $0.86 \mathrm{~V} v \mathrm{~s}$. $\mathrm{Ag} / \mathrm{AgCl}$ for the HER process. Constant potential electrolysis (CPE) has been carried out to study the bulk electrolysis of our developed protocol, which reveals that the bimetallic zinc selenolate catalyst is stable under cathodic as well as anodic potentials and generates hydrogen gas with a faradaic efficiency of $75 \%$. Preliminary studies on the heterogeneous catalyst were conducted by depositing the bimetallic zinc selenolate catalyst on the electrode surface.

Received 24th November 2021 Accepted 18th January 2022

DOI: $10.1039 / \mathrm{d} 1 \mathrm{ra0} 8614 f$

rsc.li/rsc-advances
(A) Transition metal electrocatalyst with chalcogen ligands

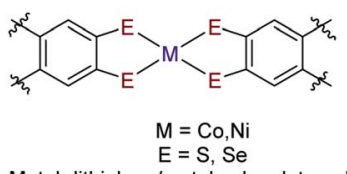

Metal dithiolene/metal selenolate polymer

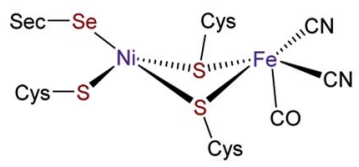

[NiFeSe]-hydrogenase the past decades, substantial progress has been made in electrochemical energy production. In hydrogen production in which protons are reduced to produce hydrogen gas, termed the hydrogen evolution reaction (HER), this occurs at the cathode. ${ }^{2}$ Generally, heavy transition metal (TM) catalytic systems augment the HER. ${ }^{3-6}$ In these catalysts, the metal ion performs the electron transfer and interacts with the substrate during bond-forming and breaking events. ${ }^{7}$ Consequently, a metal center is associated with the formation of metal hydride intermediates in the HER. Moreover, earth-abundant 3d-transition metal complexes such as those of nickel, copper, and cobalt (Scheme 1) have been prepared with the appropriate choice of organosulfur and organoselenium ligands having selenium or sulfur at the active site to interact with the proton and to assist

${ }^{a}$ Department of Chemistry, Indian Institute of Science Education and Research, Bhopal By-Pass Road, Bhauri, Bhopal 462 066, Madhya Pradesh, India. E-mail: sangitkumar@iiserb.ac.in

${ }^{b}$ Department of Chemistry, Indian Institute of Technology Indore, Khandwa Road, Simrol, Indore 453552, Madhya Pradesh, India

$\dagger$ Electronic supplementary information (ESI) available. CCDC 1949548. For ESI and crystallographic data in CIF or other electronic format see DOI: 10.1039/d1ra08614f
(B) Redox active ligand derived electrocatalysts

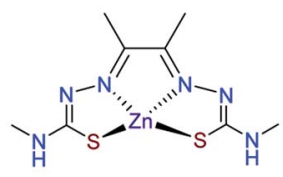

Zinc-thiosemicarbazide

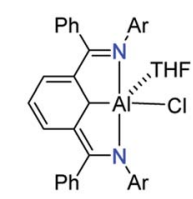

Aluminium-biaminopyridine
(C) This work

Redox inactive metal and ligand derived Bimetalic zincselenolate electrocatalyst

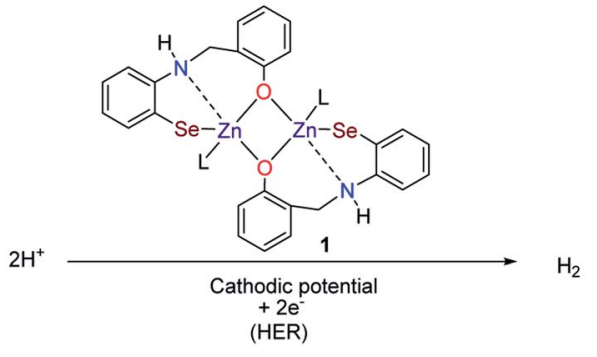

Scheme 1 Chalcogen containing ligand/complex electrocatalysts for hydrogen evolution. Catalysts in the first and second rows catalyze the reduction of protons into hydrogen gas. 
in the formation of a metal-hydride bond by the proton shuttling process, which is the crucial step in the reduction of protons in the hydrogen evolution reaction. ${ }^{8-17}$ Besides the organotransition metal selenolate electrocatalysts, selenium and transition metal ( $\mathrm{Fe}, \mathrm{Co}, \mathrm{Ni}, \mathrm{Cu}$ ) derived materials also provide an alternative for electrocatalytic proton reduction reactions (HER). ${ }^{18}$ Thus, the reactivity of metal-hydride bonds is crucial for optimum catalytic efficiency. Also, the traditional metal hydrides require open coordination sites and are able to accommodate multiple redox two-electron processes. ${ }^{\mathbf{1 9}}$

In this context, it is desirable to explore new pathways in which metal hydrides are not necessarily involved in the catalytic cycle. Further, economic and sustainable alternatives are highly desirable to ease out the dependency on the transition metals (TMs, vide infra). In 2016, Grapperhaus and co-workers reported the electrocatalytic proton reduction of acetic acid and oxidation of hydrogen gas by redox-active thiosemicarbazone ligand along with its zinc complex (Scheme 1) by avoiding the traditional metal hydride approach (Scheme 1). ${ }^{\mathbf{2 0 , 2 1}}$ Nonetheless, zinc selenolate complexes have not been reported, which could electrocatalyze HER. Sun et al. have unsuccessfully attempted electrocatalytic HER by using zinc(II)pentapyridine complex. However, the cobalt(II) complex of the same ligand was successfully able to reduce water electrocatalytically. ${ }^{22}$

From the past decade, our group has been active in the synthesis and catalytic activity of organoselenium compounds. ${ }^{23-25}$ Recently, we have reported a diorgano diselenide derived from the $o$-aminophenyl diselenide ligand, which could activate aerial oxygen towards the oxidation of organothiols. ${ }^{26,27}$ Inspired by nature ${ }^{28}$ and by the non-transition metal electrocatalysts, i.e., aluminum-bis aminopyridine (Scheme 1), for hydrogen evolution reactions (HER), ${ }^{\mathbf{2 0}, 21,29,30}$ herein, we report the synthesis and structural characterization of the novel bimetallic zinc selenolate electrocatalyst 1 that catalyzes the ligand centered hydrogen evolution reactions. Also, the catalyst has been studied in heterogeneous conditions for HER from water under an acidic medium for a longer period (7 hours). Mechanistic insights into the electrocatalytic activity of the bimetallic zinc selenolate complex were also gained by kinetic isotopic effect, EPR, and UV-visible spectroscopies.

\section{Experimental}

\section{Bis(2-aminophenyl)diselenide ${ }^{26}$}

To a DMF solution ( $8 \mathrm{~mL}$ ), CuI (173 mg, $0.9 \mathrm{mmol}, 0.2$ equiv.) and 1,10-phenanthroline (L) (164 mg, $0.9 \mathrm{mmol}, 0.2$ equiv.) was added sequentially under nitrogen atmosphere and stirred for $15 \mathrm{~min}$ at room temperature. To an orange-colored solution of CuIL, succinimide (450 mg, $4.6 \mathrm{mmol}, 1$ equiv.), 2-iodoaniline (1000 mg, $4.6 \mathrm{mmol}, 1$ equiv.), Se powder (720 mg, $9.1 \mathrm{mmol}, 2$ equiv.), and $\mathrm{K}_{2} \mathrm{CO}_{3}$ (945 mg, $6.8 \mathrm{mmol}, 1.5$ equiv.) was added in the same order and stirred the reaction for $16 \mathrm{~h}$ at $140{ }^{\circ} \mathrm{C}$. After this, the reaction mixture was poured into a brine solution (80 $\mathrm{mL}$ ) and stirred for $2 \mathrm{~h}$ at room temperature in air. Reaction mixture extracted by ethyl acetate $(25 \mathrm{~mL} \times 3)$. The combined organic layer was washed with water $(50 \mathrm{~mL})$, dried over $\mathrm{Na}_{2} \mathrm{SO}_{4}$, and evaporated on a rotatory evaporator under vacuum, which results in crystalline orange solid. Yield $1.09 \mathrm{~g}$ (70\%).

\section{Schiff base 2 (ref. 27)}

In an oven-dried round bottom flask, salicylaldehyde $(160 \mu \mathrm{L}$, $1.5 \mathrm{mmol}, 3$ equiv.) and acetic acid (8-10 drops) were added in $15 \mathrm{~mL}$ of toluene. After that, bis(2-aminophenyl)diselenide (172 mg, $0.5 \mathrm{mmol}, 1$ equiv.) was added. The flask was fitted with a water condenser and connected to Dean-Stark apparatus, and the reaction mixture was allowed to be stirred at $140{ }^{\circ} \mathrm{C}$ for $4 \mathrm{~h}$. After the full consumption of diselenide, the reaction mixture was cooled to room temperature, and the solvent was removed on the rotatory evaporator. The obtained crude solid was washed by hexane several times to afford a yellow crystalline pure Schiff base. Yield $203 \mathrm{mg}$ (74\%).

\section{Reduced Schiff base 3 (ref. 27)}

To an ethanolic solution of Schiff base 2 (138 mg, $0.25 \mathrm{mmol}, 1$ equiv.), sodium borohydride ( $38 \mathrm{mg}, 1 \mathrm{mmol}, 4$ equiv.) was added at room temperature and stirred for $4 \mathrm{~h}$ at room temperature. After that, the reaction mixture was poured into an aqueous sodium carbonate solution, and the resulted solution was stirred for $2 \mathrm{~h}$ at room temperature, followed by extraction with ethyl acetate $(25 \mathrm{~mL} \times 3)$. The extracted reaction mixture was washed with brine and dried over $\mathrm{Na}_{2} \mathrm{SO}_{4}$, and the solvent was removed under vacuum to yield a crystalline yellow colored solid. Yield $122 \mathrm{mg}$ (88\%).

\section{Bimetallic zinc selenolate complex 1}

To the stirred solution of Schiff base diselenide 2 (248 mg, $0.45 \mathrm{mmol}, 1$ equiv.) in ethanol, we added sodium borohydride (76 mg, $2.0 \mathrm{mmol}, 4$ equiv.) to generated in situ selenol and stirred the solution up to $4 \mathrm{~h}$ at room temperature. Then we added zinc chloride (122 mg, $0.9 \mathrm{mmol}, 2$ equiv.) and stirred the solution for $2 \mathrm{~h}$. After that, the solvent was removed by rotatory evaporator and the solid residue was washed with aqueous sodium bicarbonate solution several times to afford a light yellow colored novel bimetallic zinc selenolate complex 1 in (230 mg) 75\% yield. Crystallization was done in DMSO water (2:1) mixture to afford yellow colored crystals. ${ }^{1} \mathrm{H}$ NMR (400 MHz, DMSO- $\left.d_{6}\right) \delta 9.63(\mathrm{~s}, 1 \mathrm{H}), 7.29(\mathrm{~d}, J=7.3 \mathrm{~Hz}, 1 \mathrm{H}), 7.12(\mathrm{~d}, J$ $=7.3 \mathrm{~Hz}, 1 \mathrm{H}), 6.98(\mathrm{t}, J=7.5 \mathrm{~Hz}, 1 \mathrm{H}), 6.83(\mathrm{~m}, J=7.4 \mathrm{~Hz}, 2 \mathrm{H})$, $6.63(\mathrm{t}, J=7.4 \mathrm{~Hz}, 1 \mathrm{H}), 6.35(\mathrm{~d}, J=8.0 \mathrm{~Hz}, 1 \mathrm{H}), 6.22(\mathrm{t}, J=7.3 \mathrm{~Hz}$, $1 \mathrm{H}), 5.42(\mathrm{~s}, J=6.2 \mathrm{~Hz}, 1 \mathrm{H}), 4.22(\mathrm{~s}, 1 \mathrm{H}) ;{ }^{13} \mathrm{C}$ NMR $(101 \mathrm{MHz}$, DMSO- $\left.d_{6}\right) \delta 168.3,146.1,136.3,135.3,131.3,129.5,126.0,124.7$, $124.2,123.7,119.8,112.6,55.7 .{ }^{77} \mathrm{Se}$ NMR (76 MHz, DMSO- $d_{6}$ ) $\delta$-84.7. HRMS of $[\mathrm{M}+\mathrm{H}]^{+}=682.8659$, found 682.8652. Anal. calcd for $\mathrm{C}_{26} \mathrm{H}_{22} \mathrm{Zn}_{2} \mathrm{~N}_{2} \mathrm{O}_{2} \mathrm{Se}_{2} \cdot \mathrm{H}_{2} \mathrm{O}$ : C 44.54, $\mathrm{H}$ 3.45, N 4.10, found: C 44.94, H 3.75, N 3.98\%. IR data (solid) in $\mathrm{cm}^{-1}$ : 3015.9, 1738.6, 1584.5, 1480.9, 1446.8, 1365.7, 1229.4, 839.2, 747.0, 716.8 .

\section{Monometallic mercuric selenolate complex 4}

The standard elemental mercury (108 mg, $0.54 \mathrm{mmol}, 1$ equiv.) was added to the stirred ethanolic solution of reduced 
diselenide 3 (300 mg, $0.54 \mathrm{mmol}, 1$ equiv.) at room temperature for 3 days which results in the insertion of $\mathrm{Hg}$ into $\mathrm{Se}-\mathrm{Se}$ bond of reduced diselenide 3 . Then the reaction mixture was filtered over Celite, and solvent was removed under rotatory evaporator to afforded a green colored monometallic mercury selenolate complex 4. Yield $327 \mathrm{mg}(80 \%) .{ }^{1} \mathrm{H}$ NMR (400 MHz, DMSO-d 6 ) $\delta 7.29(\mathrm{~d}, J=7.3 \mathrm{~Hz}, 1 \mathrm{H}), 7.12(\mathrm{~d}, J=7.3 \mathrm{~Hz}, 1 \mathrm{H}), 6.98(\mathrm{t}, J=$ $7.5 \mathrm{~Hz}, 1 \mathrm{H}), 6.83(\mathrm{q}, J=7.3 \mathrm{~Hz}, 2 \mathrm{H}), 6.63(\mathrm{t}, J=7.4 \mathrm{~Hz}, 1 \mathrm{H}), 6.35$ $(\mathrm{d}, J=8.0 \mathrm{~Hz}, 1 \mathrm{H}), 6.22(\mathrm{t}, J=7.3 \mathrm{~Hz}, 1 \mathrm{H}), 4.22(\mathrm{~d}, J=5.1 \mathrm{~Hz}$, $2 \mathrm{H}) ;{ }^{13} \mathrm{C}$ NMR $\left(101 \mathrm{MHz}, \mathrm{DMSO}-d_{6}\right) \delta 155.3,148.9,137.2,128.6$, $128.2,127.9,125.7,119.3,116.6,115.2,114.4,110.4,42.4 ;{ }^{77} \mathrm{Se}$ NMR (76 MHz, DMSO-d 6 ) $\delta$ 75.7. Anal. calcd for $\mathrm{C}_{26} \mathrm{H}_{24} \mathrm{HgN}_{2}$ $\mathrm{O}_{2} \mathrm{Se}_{2}$ : C 41.36, H 3.20, N 3.71, found: C 42.94, H 2.94, N 4.04\%. HRMS of $[\mathrm{M}+\mathrm{H}]^{+}=758.9956$, found 758.9977. IR data (solid) in $\mathrm{cm}^{-1}: 3379.9,2970.4,1738.4,1640.1,1454.4,1365.7,1229.1$, 1217.1, 1102.6, 984.1, 745.7.

\section{X-ray crystallography}

Suitable crystals of compounds were obtained by slow evaporation of their solutions. The single-crystal diffraction studies were carried out on a Bruker APEX II diffractometer (Mo-K $\alpha, \lambda=$ $0.71069 \AA$ ). All crystal structures were solved by direct methods. The program SAINT (version 6.22) was used for integration of the intensity of reflections and scaling. The program SADABS was used for absorption correction. The crystal structures were solved and refined using the SHELXTL package. All hydrogen atoms were included in idealized positions, and a riding model was used. Non-hydrogen atoms were refined with anisotropic displacement parameters.

\section{Electrochemical measurements}

A potentiostat (CHI 760D, CH Instruments, TX, USA) biopotentiostat instrument was used for electrochemical measurements. The three-electrode electrochemical cell consisted of a glassy carbon ( $3 \mathrm{~mm}$ diameter, $0.07 \mathrm{~cm}^{2}$ surface area) as the working electrode, a nonaqueous $\mathrm{Ag} / \mathrm{AgNO}_{3}(10 \mathrm{mM}$ $\left.\mathrm{AgNO}_{3}\right)$ and aqueous $\mathrm{Ag} / \mathrm{AgCl}(0.1 \mathrm{M} \mathrm{KCl})$ as a reference electrode, and a platinum wire as a counter electrode were used for the electrochemical measurements.

\section{Constant potential electrolysis (CPE)}

For electrocatalytic HER, CPE was carried out using $\mathrm{Hg}$ pool (surface area $3.5 \mathrm{~cm}^{2}$ ) as a working electrode, $\mathrm{Pt}$ mesh as a counter electrode and $\mathrm{Ag} / \mathrm{AgCl}(1.0 \mathrm{M} \mathrm{KCl})$ as a reference electrode. A methanolic solution of catalyst 1 (3 mM) and acetic acid (12 mM) was kept at $-1.57 \mathrm{~V} v s$. NHE for 30 minutes. The evolved hydrogen gas was confirmed by Gas Chromatogram equipped with Thermal Conductivity Detector (GCTCD) using Shimadzu GC-2014 system.

\section{Results and discussion}

\section{Synthesis and characterization}

Precursor Schiff base and its reduced diselenides 2 (ref. 27) and 3 (ref. 27) were synthesized by the copper-catalyzed method in gram quantity (Scheme 2). ${ }^{26}$

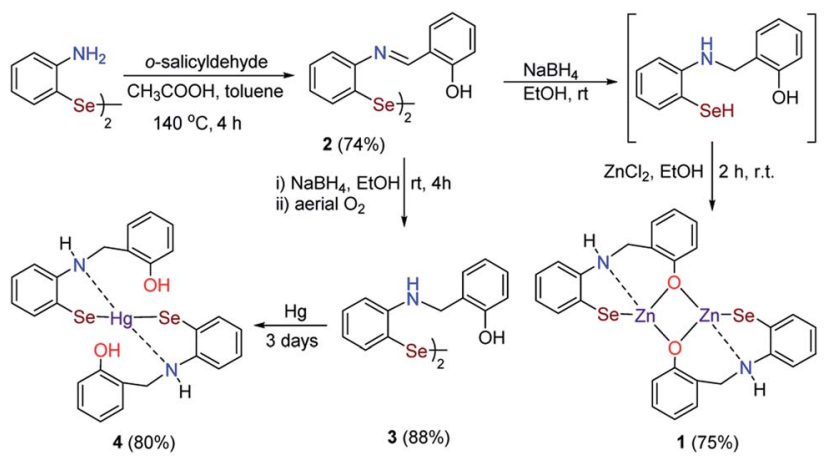

Scheme 2 Synthesis of zinc and mercuric selenolate 1 and 4 .

The reduction of Schiff base diselenide 2 with an excess of sodium borohydride generated selenol in situ, which upon reaction with zinc chloride, afforded a light yellow colored novel bimetallic zinc selenolate 1 in $75 \%$ yield. Crystallization from DMSO and water mixture afforded yellow crystalline solid. Next, we attempted to isolate the mercury analog of zinc complex 4. The reaction of mercury chloride with in situ generated selenol afforded a complex mixture, and isolation of any mercury selenolate complex was unsuccessful despite several attempts. Standard elemental mercury insertion reaction into the Se-Se bond afforded a monometallic mercury selenolate complex 4. It is worth noting that, despite several reports on the structurally characterized mercury selenolate complexes, limited examples of structurally characterized zinc selenolates are available. ${ }^{31-38}$ Herein, suitably positioned nitrogen and oxygen donor atoms in the ligand presumably stabilized bimetallic zinc core. Characterization of zinc and mercury selenolate complexes 1 and 4 by ${ }^{77}$ Se NMR, which is a very sensitive technique towards the electronic environment around the selenium nucleus, revealed significantly downfield shift ( $\delta=-85$ and $76 \mathrm{ppm}$, respectively) as compared to the diselenide 3 ( $\delta=400 \mathrm{ppm})$.

\section{Structural determination}

The solid-state crystal structure of $\mathbf{1}$ was obtained from DMSO and water mixture afforded yellow crystalline solid and is air stable for several days. The molecular structure of the bimetallic zinc selenolate $\mathbf{1}$ is determined by single-crystal X-ray diffraction analysis (Fig. 1). The structure refinement parameters for 1 is given in Table 1 while the selected bond lengths and bond angles are given in Table 2. ORTEP diagrams of the crystal structures has shown in Fig. 1.

The crystal structure of bimetallic zinc selenolate 1. 2DMSO reveals the average bond distance of 2.44(7) A between Zn and Se and is comparable with the previously reported Se1-Zn1 bond distances, which are in the range of 2.313(3)-2.463(6) $\AA$ (Table 2). ${ }^{31-37}$ The average Zn1-N1 bond distance is 2.199(3) A, equivalent to those reported for zinc and typical $\mathrm{N}$-donor ligands, which generally range from 2.04 to $2.14 \AA$ (Table 2). The average $\mathrm{C}-\mathrm{Se}-\mathrm{Zn}$ angle is $89.34(1)$, lower than the already reported value $97.45-99.26(17) .{ }^{32-37}$ The average Se1-Zn1-N1 chelate bite angle is $82.22(9)^{\circ}$, and this is comparable to that 


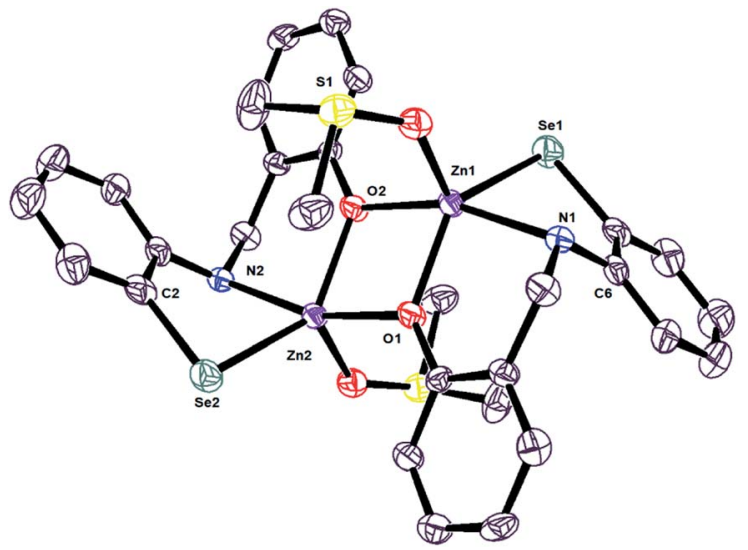

Fig. 1 ORTEP view of bimetallic zinc selenolate complex 1. 2DMSO (ORTEP view of 1 with $60 \%$ thermal ellipsoid probability).

reported for $\left[\mathrm{Zn}\left\{\mathrm{But}_{2} \mathrm{P}-(\mathrm{Se}) \mathrm{NPri}\right\}_{2}\right]\left[81.37(9)^{\circ}\right] .^{32}$ This smaller bite angle leads to the larger bite angle of $\mathrm{Zn} 1-\mathrm{O} 1-\mathrm{Zn} 2$ [101.83(1) ${ }^{\circ}$ (Table 2).

The two sides i.e., Zn2-O2 = Zn1-O1 (2.031 $)$ and Zn1-O2 = Zn2-O1 (2.057 ̊̊) and angles i.e., $\angle \mathrm{Zn} 2 \mathrm{O} 2 \mathrm{Zn} 1=\angle \mathrm{Zn} 2 \mathrm{O} 1 \mathrm{Zn} 1$ $\left(101.83^{\circ}\right)$ and $\angle \mathrm{O} 1 \mathrm{Zn} 1 \mathrm{O} 2=\angle \mathrm{O} 1 \mathrm{Zn} 2 \mathrm{O} 2\left(78.17^{\circ}\right)$ are equal. Both $\mathrm{Zn}$ and phenolic oxygen binds cyclically and form a parallelogram, which is a stable geometry ${ }^{39}$ and could be the reason for structural stability. The metal center $\mathrm{Zn}$ is tetra coordinately bonded with the ligand, and DMSO is ligated to the fifth coordination site, which could be a potential position for ligand exchange.

Table 1 Crystal data and structure refinement for 1

$\begin{array}{ll}\text { CCDC no. } & 1949548 \\ \text { Formula weight } & 420.69 \\ \text { Temperature } & 164(2) \mathrm{K} \\ \text { Wavelength } & 0.71073 \AA \\ \text { Crystal system } & \text { Triclinic } \\ \text { Space group } & P \overline{1} \\ \text { Unit cell dimensions } & a=8.4306(14) \AA \quad \alpha=76.941(6)^{\circ} \\ & b=9.2108(16) \AA \quad \beta=88.026(5)^{\circ} \\ & c=10.5745(18) \AA \quad \gamma=75.718(6)^{\circ} \\ \text { Volume } & 775.0(2) \AA^{3} \\ Z & 2 \\ \text { Density (calculated) } & 1.803 \mathrm{mg} \mathrm{m}^{-3} \\ \text { Absorption coefficient } & 4.070 \mathrm{~mm}^{-1} \\ F(000) & 422 \\ \text { Crystal size } & 0.23 \times 0.18 \times 0.15 \mathrm{~mm}^{3} \\ \text { Theta range } & 2.494^{\circ} \text { to } 30.033^{\circ} \\ \text { Index ranges } & -11 \leq h \leq 11,-12 \leq k \leq 12,0 \leq l \leq \\ & 14 \\ \text { Reflections collected } & 4284 \\ \text { Independent reflections } & 4284 \\ \text { Completeness } & 99.9 \% \\ \text { Refinement method } & \text { Full-matrix least-squares on } F^{2} \\ \text { Data/restraints/parameters } & 4284 / 0 / 196 \\ \text { Goodness-of-fit on } F^{2} & 0.882 \\ \text { Final } R \text { indices }[I>2 \text { 2sigma }(I)] & R_{1}=0.0477, \mathrm{w}_{2}=0.1104 \\ R \text { indices (all data) } & R_{1}=0.1034, \mathrm{w} R_{2}=0.1405 \\ \text { Largest diff. peak and hole } & 0.818 \text { and }-0.665 \text { e } \AA^{-1} \\ & \end{array}$

Table 2 Selected bond length $[\AA \AA]$ and bond angle $\left({ }^{\circ}\right)$ for 1

\begin{tabular}{llll}
\hline Se1-Zn1 & $2.4455(7)$ & Zn2-N2 & $2.199(3)$ \\
Zn1-O1 & $2.031(3)$ & Zn2-O2 & $2.031(3)$ \\
Zn1-N1 & $2.199(3)$ & Se2-Zn2 & $2.4455(7)$ \\
Zn1-O2 & $2.058(3)$ & Zn2-O1 & $2.058(3)$ \\
O1-Zn1-O2 & $78.2(1)$ & Se2-Zn2-N2 & $82.22(9)$ \\
Zn2-O1-Zn1 & $101.8(1)$ & Zn1-N1-C6 & $108.7(3)$
\end{tabular}

\section{Electrochemical studies}

The Cyclic Voltammetry (CV) of the zinc selenolate $\mathbf{1}$ have been studied under cathodic and anodic potential in dry acetonitrile, methanol, and propylene carbonate solvents, respectively, using a glassy carbon working electrode.

The CV of zinc selenolate complex $1(1 \mathrm{mM})$ in acetonitrile shows one broad reduction wave at $-0.92 \mathrm{~V} v s$. $\mathrm{Ag} / \mathrm{AgCl}$ (the potentials presented in this study are referenced to it) under cathodic potential (Fig. S1, ESI†), which corresponds to the reduction of the ligand as LUMO is situated at the ligand core of the complex (Fig. S29†). At the low scan rate, the broad reduction wave $(-0.92 \mathrm{~V})$ was well resolved into two successive oneelectron reduction waves (at $-0.96 \mathrm{~V}$ and -1.09 , Fig. S2, ESI $\dagger$ ). This was further supported by differential pulse voltammetry (DPV, Fig. S3, ESI†). The controlled potential electrolysis experiment also confirmed the stoichiometry of the electron, which calculated as $1.88 .^{40}$ The CV study of diselenide ligand 3 has also been studied, which shows similar behavior (with reduction waves at $-0.93 \mathrm{~V}$ and $-1.13 \mathrm{~V}$ ) like zinc selenolate complex 1 (Fig. S4, ESI $\dagger$ ).

Next, the CV of zinc selenolate $\mathbf{1}$ and ligand $\mathbf{3}$ was recorded at various scan rates $\left(0.1\right.$ to $3.5 \mathrm{~V} \mathrm{~s}^{-1}$ ) in methanol (Fig. S5-S8†) under cathodic potential. The peak current increases linearly with the change in scan rate, and the experimentally calculated diffusion coefficient $\left(D_{0}\right)$ for complex 1 and ligand 3 is $5.3 \times$ $10^{-6}$ and $19.3 \times 10^{-6} \mathrm{~cm}^{2} \mathrm{~s}^{-1}$ in methanol, which suggests that the reduction reaction is diffusion-limited and the complex $\mathbf{1}$ is suitable for the electrocatalysis.

\section{Electrocatalysis}

The electrocatalytic properties of the bimetallic zinc selenolate $\mathbf{1}$ were performed in a custom-made, single apartment cell with a glassy carbon working electrode, Pt wire counter electrode, and $\mathrm{Ag} / \mathrm{AgCl}$ wire reference electrode. The electrochemical solution of zinc selenolate complex 1 in methanol shows the catalytic cathodic current for the hydrogen evolution reaction in the presence of acetic acid (Fig. S9†). The cathodic current increases with increasing the concentration of acetic acid at $-1.78 \mathrm{~V}$ vs. $\mathrm{Ag} / \mathrm{AgCl}$, which confirms the electrocatalytic reduction of the protons. The current plateaus at $12 \mathrm{mM}$ show acid saturation with a high current density (Fig. S9†). Also, the maximum turnover frequency (TOF) of $509 \mathrm{~s}^{-1}$ was realized at $12 \mathrm{mM}$. The onset overpotential was determined by plotting the current-voltage diagram (Tafel plot, Fig. S10, ESI $\dagger$ ). Tafel analysis gives the overpotential value of $0.86 \mathrm{~V} v s$. $\mathrm{Ag} / \mathrm{AgCl}$ for the hydrogen evolution reaction. The production of catalytic $\mathrm{H}_{2}$ gas has been supported by the simultaneous formation of large 
amounts of gas bubbles on the electrode surface of the glassy carbon working electrode. The catalytic current $\left(i_{\text {cat }}\right)$ at the $12 \mathrm{mM}$ acid concentration shows a linear dependency on the scan rate, which indicates that the current is limited by acid diffusion to the electrode surface (Fig. S11, ESI $\dagger$ ). Similarly, a linear plot for $i_{\text {cat }} v s$. [catalyst 1] was observed upon varying the concentration of zinc selenolate catalyst 1 , which suggests firstorder reaction kinetics with respect to catalyst 1 (Fig. S12, ESI $\dagger$ ).

Next, organodiselenide ligand 3 was evaluated as a catalyst for hydrogen evolution reaction. The organo diselenide 3 displayed an irreversible reduction peak at $-1.85 \mathrm{~V} v s . \mathrm{Ag} / \mathrm{AgCl}$ in methanol (vide supra). Upon addition of a successive amount of acetic acid, the current plateaus increase steadily and show at a maximum current density at $14 \mathrm{mM}$ acetic acid (Fig. S13, $\mathrm{ESI} \dagger$ ). The calculated maximum TOF for diselenide ligand 3 (25 $\mathrm{s}^{-1}$ ) was low compared to the zinc selenolate complex 1 (Fig. S14, ESI $\dagger$ ).

Heavier analog mercury selenolate 4 failed to catalyze the hydrogen evolution reaction (HER). Mercury selenolate 4 was found unstable under negative potential as deposition was observed on the surface of the working electrode, presumably due to reduced mercury and could be due to feasible standard reduction potential $\left(E_{\mathrm{Hg}^{2+} / \mathrm{Hg}^{0}}=+0.74 \mathrm{~V} v s\right.$. SHE $)$ of mercury ion to mercury than that of hydrogen ion to $\mathrm{H}_{2}$.

\section{Heterogeneous studies}

For this, firstly, $7 \mathrm{mg}$ of catalyst 1 was dispersed in a mixture of $1.0 \mathrm{mg}$ PVDF (polyvinylidene fluoride) binder and $1 \mathrm{~mL}$ solution of water-ethanol $(8: 2, \mathrm{v} / \mathrm{v})$. This solution $(100 \mu \mathrm{L})$ was dropped cast on the GC electrode surface and dried for 30 minutes in the heating oven at $90{ }^{\circ} \mathrm{C}$ to obtain a heterogenized GC electrode.

The comparison of the HER with and without heterogenized GC electrode has also been made to understand the role of zinc selenolate $\mathbf{1}$ under heterogeneous conditions (Fig. 2). The electrocatalyst 1 deposited heterogenized GC electrode displayed a high catalytic current density of 1.21 $\mathrm{mA} \mathrm{cm}{ }^{-2}$ with an onset potential of $-0.55 \mathrm{~V} v s$. Ag/AgCl under acidic conditions ( $0.5 \mathrm{M} \mathrm{H}_{2} \mathrm{SO}_{4}$, Fig. S16, ESI $\left.\dagger\right)$. It is difficult to compare the current densities in HER catalyzed by the zinc selenolate 1 under heterogeneous conditions with the earlier reported heterogeneous catalysts because of different conditions applied, ${ }^{\mathbf{9}, 11}$ nevertheless, significantly high current densities were realized under heterogenized electrocatalyst $\mathbf{1}$.

\section{Constant potential electrolysis}

The stability of zinc selenolate catalyst $\mathbf{1}$ under hydrogen evolution reaction conditions is studied by constant potential electrolysis (CPE) at an applied potential of $-1.85 \mathrm{~V}$ (vs. $\mathrm{Ag} / \mathrm{AgCl}$ for HER) at the bulk electrode surface in which a significant change in current was not observed for 7-8 hours (Fig. S17, ESI $\dagger$ ). The UV-visible study was also performed on the solution from electrolysis cell after and before bulk electrolysis (Fig. S18, ESI $\dagger$ ). The characteristic absorbance at $380 \mathrm{~nm}$ of zinc selenolate catalyst $\mathbf{1}$ was noticed nearly identical to the one before

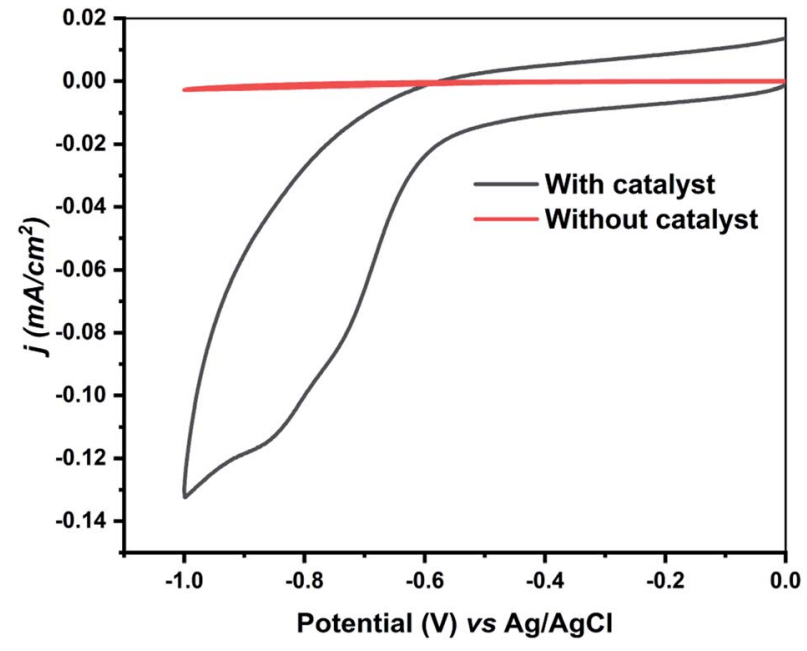

Fig. 2 The cyclic voltammogram of zinc selenolate 1 loaded onto a glassy carbon electrode in a cathodic potential window using $0.5 \mathrm{M}$ $\mathrm{H}_{2} \mathrm{SO}_{4}$ solution as electrolytes at the scan rate $(\nu)$ of $0.05 \mathrm{~V} \mathrm{~s}^{-1}$.

electrolysis confirms that the structure of catalyst 1 remains unchanged after the electrocatalysis. Furthermore, catalyst $\mathbf{1}$ was screened for FTIR analysis before and after the bulk electrolysis under cathodic potential, respectively (Fig. S19, ESI $\dagger$ ). The FTIR spectra do not show any significant change in the characteristic frequencies. Next, we examined the stability of catalyst 1 in electrolytic solution during CV scans under cathodic potential (Fig. S20†), where no visible change was observed, which confirms that catalyst $\mathbf{1}$ is stable during HER. Moreover, the stability of catalyst 1 was also confirmed under heterogeneous conditions by screening the heterogenized catalyst $\mathbf{1}$ for the electrolysis under acidic conditions for the long hour periods (up to $7 \mathrm{~h}$ ), which further screened for the EDX study (Fig. S21, ESI $\dagger$ ). The EDX study of the electrode surface does not show any change in the composition of zinc and selenium, which confirms the stability of complex 1 (Fig. S21, ESI $\dagger$ ). These results demonstrate that the bimetallic zinc selenolate complex 1 serves as a robust catalyst for HER. The evolved hydrogen gas in the HER during CPE was quantified. Under cathodic potential, which revealed a faradaic efficiency of $75 \%$ for hydrogen gas (Fig. S22-S25 and Scheme S2, $\left.\mathrm{ESI}^{\dagger}\right)$. In comparison, the diselenide ligand shows faradaic efficiency of $28 \%$ only for electrocatalytic HER (Page S29, ESI $\dagger$ ). An additional control experiment was performed after prolonged electrolysis to confirm whether the ligand or complex is decomposing onto the surface of the electrode surface as a possible source of catalysis. Therefore, a chronoamperometry study was performed for $2 \mathrm{~h}$ on a solution containing catalyst 1 $(1 \mathrm{mM}),{ }^{n} \mathrm{Bu}_{4} \mathrm{NPF}_{6}(0.1 \mathrm{M})$, and acetic acid $(12 \mathrm{mM})$. The electrode was then removed, rinsed with DI water, and placed in a new cell containing $12 \mathrm{mM}$ acid and $0.1 \mathrm{M}{ }^{n} \mathrm{Bu}_{4} \mathrm{NPF}_{6}$ in methanol for a chronoamperometry test of $2 \mathrm{~h}$ (Fig. S26, ESI $\dagger$ ). For complex 1, an appreciable charge was produced, while after rinsing with DI water, no significant charge above the acid blank was observed. This experiment indicates that 
electrocatalytically active films are not generated over the time frame of electrolysis.

\section{Control experiments}

EPR spectroscopy. EPR experiment was conducted on the reaction mixture at low temperature to have insight into the reaction intermediates involved in HER. For this purpose, we performed the constant potential electrolysis at $-1.85 \mathrm{~V} v s . \mathrm{Ag} /$ $\mathrm{AgCl}$, and an aliquot of the reaction mixture was immediately frozen at $-78{ }^{\circ} \mathrm{C}$. An EPR spectrum of the sample showed a singlet at $3232.61 \mathrm{G}$ with a $g$ value at 2.08212 , which suggests that a radical species presumably a selenium-centered radical (Fig. 3). ${ }^{41}$

Spectroelectrochemistry. UV-visible spectroscopic studies were performed on the reaction mixture to understand the formation of an intermediate during electrocatalysis. For this, the UV-visible spectra of the reaction mixture were also recorded under cathodic potential. The absorption spectra show the growth of the absorption band near $385 \mathrm{~nm}$ and a decrease in the absorption band near $585 \mathrm{~nm}$ and $274 \mathrm{~nm}$ with an isosbestic point at $447 \mathrm{~nm}$ and $336 \mathrm{~nm}$ (Fig. S27, ESI $†$ ).

Proposed homogeneous HER mechanism. Based on the control experiment and literature,,$^{\mathbf{8 , 1 0 , 2 0 , 4 2 - 4 4}}$ a mechanism has been proposed for HER (Scheme 3).

Based on control experiments, it is reasonable to assume that the hydrogen evolution reaction catalyzed by the synthesized zinc selenolate complex 1 could initiate by the solvent exchange with the acetic acid at the Lewis acidic zinc center to form acetic acid zinc complex 1a (Fig. S30, ESI $\dagger$ and Scheme 3) as the protonation of the selenium center was not observed by the addition of the acetic acid to $\mathbf{1}$ and also to the diselenide ligand 3 as monitored by ${ }^{77}$ Se NMR and UV-visible absorption. One-electron reduction of $\mathbf{1}$ could form radical anion $\mathbf{1 b}$ at $-0.68 \mathrm{~V}$. The formation of radical anion $\mathbf{1 b}$ is also supported by the EPR spectrum (Fig. 3, vide supra). Further reduction of $\mathbf{1 b}$ at

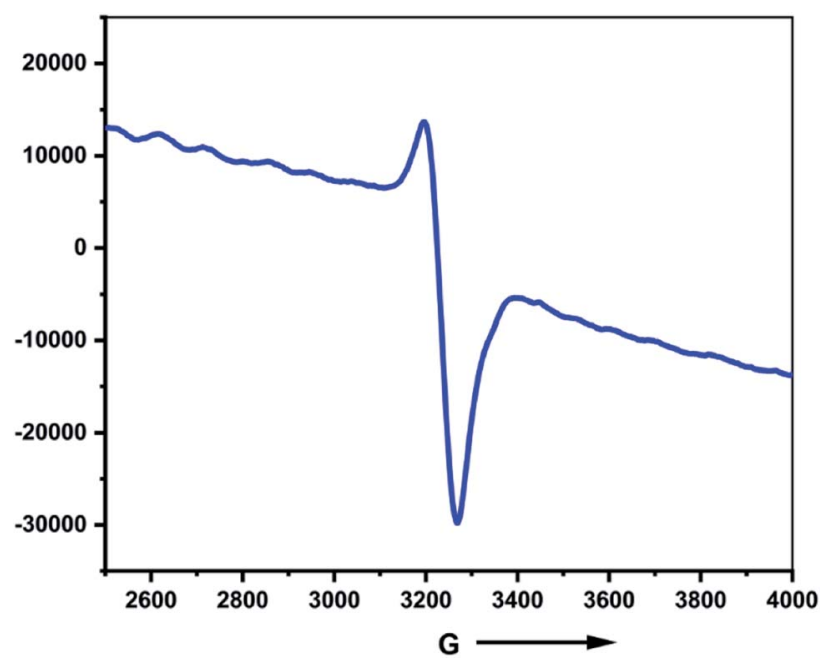

Fig. 3 EPR spectra of the reaction mixture during CPE in cathodic potential.

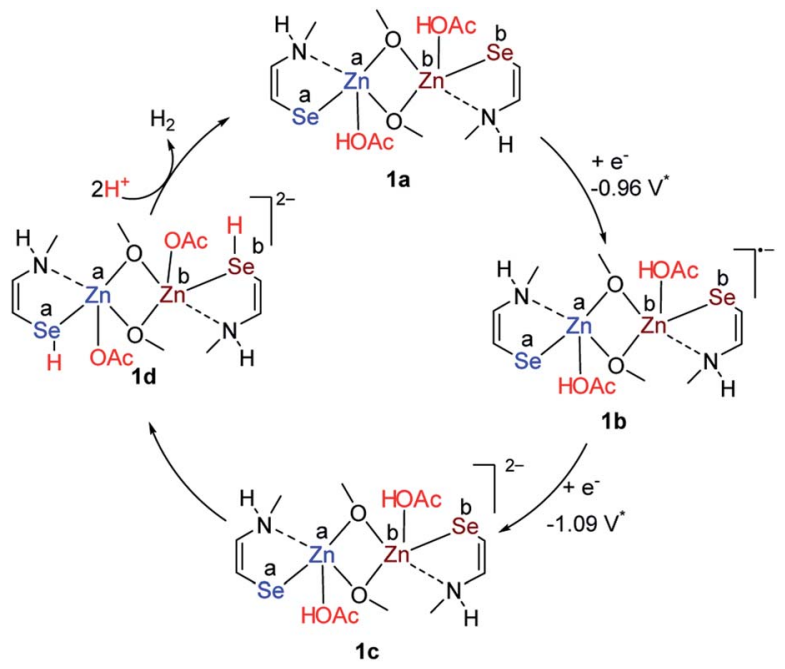

Scheme 3 Mechanistic pathway for HER from acetic acid (* for the reduction potential taken in acetonitrile solvent).

$-0.81 \mathrm{~V}$ could lead to the formation of zinc selenolate dianion 1c. Both cathodic potentials of -0.96 and $-1.09 \mathrm{~V}$ were experimentally obtained by recording $\mathrm{CV}$ and differential pulse voltammetry (DPV) of catalyst 1 in acetonitrile. The intramolecular proton transfer from acetate to selenium due to the better nucleophilic character of the selenium to form zinc selenol dianion 1d. ${ }^{4-48}$ The selenol intermediate 1d could liberate hydrogen to complete the cycle and form $\mathbf{1 a}$.

\section{Conclusions}

In summary, a novel bimetallic zinc selenolate has been synthesized and structurally characterized. Further, bimetallic zinc selenolate electrocatalyzed the hydrogen evolution reactions (HER) that could complement TM catalysts and redoxactive ligands. The synthesized complex catalyzed the hydrogen evolution reaction (HER) with a remarkably high TOF value of $509 \mathrm{~s}^{-1}$ via a ligand-assisted pathway avoiding the formation of metal hydrides during catalysis. The ligand diselenide 3 alone electrocatalyzed HER with a low TOF value of 25 $\mathrm{s}^{-1}$, also $\mathrm{ZnCl}_{2}$ alone failed to exhibit HER and by combining these two in complex 1 show the catalytic activity where the Lewis acidity of $\mathrm{Zn}$ (II) plays a vital role in the mechanism as it binds with the substrate acetic acid and then would help in the transfer of a proton from ligated acetic acid. The reaction mainly occurs at the selenium center for the two-electron transfer in hydrogen evolution reaction (HER), while the Lewis acidic $\mathrm{Zn}$ (II) center brings the substrate near to the active selenium center. Furthermore, the zinc selenolate electrocatalyst has been heterogenized on the GC electrode, which catalyzed the HER in acidic solution under cathodic potentials, respectively. The zinc selenolate catalyst shows stability for extended hours (up to $7 \mathrm{~h}$ ) under acidic solutions in homogenous and heterogeneous catalysis, which proves the worthiness of the catalyst for the future. Further progress is being made to enhance the reactivity of ligand in the bimetallic selenolate 
complexes to synergistically activate the small molecules, as we have presented here.

\section{Author contributions}

SK and AU designed the research. AU, SKV and EV performed the CV study and analyzed by AP. SK, AU, and AP wrote the manuscript. SKS and MKA analyzed and quantified the hydrogen gas evolved in the HER by GC-TCD. All authors have given approval to the final version of the manuscript.

\section{Conflicts of interest}

There are no conflicts to declare.

\section{Acknowledgements}

SK acknowledges DST-SERB (CRG/2019/000017) New Delhi and IISER Bhopal for financial support. AP acknowledges DST-SERB (CRG/2020/002493) for financial support. Professor R. J. Butcher (Howard University, Washington) for resolving the crystal structure of 1 (CCDC no. 1949548). Miss Sulekha Sharma and Palak Mehra are kindly acknowledged for assisting in the electrochemical experiments. Authors sincerely thank the Department of Chemistry at IISER Bhopal for providing single crystal XRD, and scanning electron microscopy facilities. The authors also gratefully acknowledge High-Performance Computing facilities provided by IISER Bhopal.

\section{References}

1 W. Seh, J. Kibsgaard, C. F. Dickens, I. Chorkendorff, J. K. Nørskov and T. F. Jaramillo, Science, 2017, 355, 4998.

2 M. D. Symes and L. Cronin, Nat. Chem., 2013, 5, 403-409.

3 H. I. Karunadasa, C. J. Chang and J. R. Long, Nature, 2010, 464, 1329-1333.

4 H. I. Karunadasa, E. Montalvo, Y. Sun, M. Majda, J. R. Long and C. J. Chang, Science, 2012, 335, 698-702.

5 J. P. Porcher, T. Fogeron, M. Gomez-Mingot, E. Derat, L. M. Chamoreau, Y. Li and M. Fontecave, Angew. Chem., Int. Ed., 2015, 54, 14090-14093.

6 P. Yadav, I. Nigel-Etinger, A. Kumar, A. Mizrahi, A. Mahammed, N. Fridman, S. Lipstman, I. Goldberg and Z. Gross, iScience, 2021, 24, 102924.

7 E. J. Sundstrom, X. Yang, V. S. Thoi, H. I. Karunadasa, C. J. Chang, J. R. Long and M. Head-Gordon, J. Am. Chem. Soc., 2012, 134, 5233-5242.

8 B. H. Solis and S. Hammes-Schiffer, J. Am. Chem. Soc., 2012, 134, 15253-15256.

9 C. A. Downes and S. C. Marinescu, J. Am. Chem. Soc., 2015, 137, 13740-13743.

10 C. Wombwell, C. A. Caputo and E. Reisner, Acc. Chem. Res., 2015, 48, 2858-2865.

11 C. A. Downes and S. C. Marinescu, ACS Catal., 2017, 7, 848854 .

12 C. A. Downes, J. W. Yoo, N. M. Orchanian, R. Haiges and S. C. Marinescu, Chem. Commun., 2017, 53, 7306-7309.
13 K. Koshiba, K. Yamauchi and K. Sakai, Angew. Chem., Int. Ed., 2017, 56, 4247-4251.

14 T. Straistari, J. Fize, S. Shova, M. Réglier, V. Artero and M. Orio, ChemCatChem, 2017, 9, 2262-2268.

15 C. Wombwell and E. Reisner, Dalton Trans., 2014, 43, 44834493.

16 G. Gezer, S. Verbeek, M. A. Siegler and E. Bouwman, Dalton Trans., 2017, 46, 13590-13596.

17 C. Pieri, A. Bhattacharjee, A. Barrozo, B. Faure, M. Giorgi, J. Fize, M. Réglier, M. Field, M. Orio, V. Artero and R. Hardré, Chem. Commun., 2020, 56, 11106-11109.

18 X. Xia, L. Wang, N. Sui, V. L. Colvinc and W. W. Yu, Nanoscale, 2020, 12, 12249-12262.

19 G.-G. Luo, H.-L. Zhang, Y.-W. Tao, Q.-Y. Wu, D. Tianc and Q. Zhang, Inorg. Chem. Front., 2019, 6, 343-354.

20 A. Z. Haddad, B. D. Garabato, P. M. Kozlowski, R. M. Buchanan and C. A. Grapperhaus, J. Am. Chem. Soc., 2016, 138, 7844-7847.

21 S. P. Cronin, A. A. Mamun, M. J. Toda, M. S. Mashuta, Y. Losovyj, P. M. Kozlowski, R. M. Buchanan and C. A. Grapperhaus, Inorg. Chem., 2019, 58, 12986-12997.

22 Y. Sun, J. P. Bigi, N. A. Piro, M. L. Tang, J. R. Long and C. J. Chang, J. Am. Chem. Soc., 2011, 133, 9212-9215.

23 A. Verma, S. Jana, C. D. Prasad, A. Yadav and S. Kumar, Chem. Commun., 2016, 52, 4179-4182.

24 S. Kumar, J. Yan, J.-f. Poon, V. P. Singh, X. Lu, M. K. Ott, L. Engman and S. Kumar, Angew. Chem., Int. Ed., 2016, 55, 3729-3733.

25 Water as an oxidant: S. Jana, A. Verma, R. Kadu and S. Kumar, Chem. Sci., 2017, 8, 6633-6644.

26 S. J. Balkrishna, B. S. Bhakuni and S. Kumar, Tetrahedron, 2011, 67, 9565-9575.

27 V. Rathore, A. Upadhyay and S. Kumar, Org. Lett., 2018, 20, 6274-6278.

28 N. Cox, D. A. Pantazis, F. Neese and W. Lubitz, Interface Focus, 2015, 5, 20150009.

29 S. Qi, Y. Fan, J. Wang, X. Song, W. Li and M. Zhao, Nanoscale, 2020, 12, 306-315.

30 E. J. Thompson and L. A. Berben, Angew. Chem., Int. Ed., 2015, 54, 11642-11646.

31 M. Bochmann, G. C. Bwembya, R. Grinter, A. K. Powell and K. J. Webb, Inorg. Chem., 1994, 33, 2290-2296.

32 G. Mugesh, H. B. Singh, R. P. Patel and R. J. Butcher, Inorg. Chem., 1998, 37, 2663-2669.

33 C. Santi, S. Santoro, B. Battistelli, L. Testaferri and M. Tiecco, Eur. J. Org. Chem., 2008, 2008, 5387-5390.

34 T. J. Emge, M. D. Romanelli, B. F. Moore and J. G. Brennan, Inorg. Chem., 2010, 49, 7304-7312.

35 A. Pöllnitz, C. Silvestru, J.-F. Carpentierb and A. Silvestru, Dalton Trans., 2012, 41, 5060-5070.

36 C. N. Babu, K. Srinivas and G. Prabusankar, Dalton Trans., 2016, 45, 6456-6465.

37 M. Maruthupandi and G. Prabusankar, RSC Adv., 2020, 10, 28950-28957.

38 S. Patel, Meenakshi, A. S. Hodage, A. Verma, S. Agrawal, A. Yadav and S. Kumar, Dalton Trans., 2016, 45, 4030-4040. 
39 O. Byer, B. F. Lazebnik and D. L. Smeltzer, Methods for Euclidean Geometry, Mathematical Association of America, 2010, vol. 37, p. 51.

40 B. Tulyathan and W. E. Geiger, J. Am. Chem. Soc., 1985, 107, 5960-5967.

41 S. Zhang, X. Wang, Y. Su, Y. Qiu, Z. Zhang and X. Wang, Nat. Commun., 2014, 5, 4127.

42 B. Mondal, K. Sengupta, A. Rana, A. Mahammed, M. Botoshansky, S. G. Dey, Z. Gross and A. Dey, Inorg. Chem., 2013, 52, 3381-3387.

43 S. Dey, A. Rana, S. G. Dey and A. Dey, ACS Catal., 2013, 3, 429-436.
44 Z. Haddad, D. Kumar, K. O. Sampson, A. M. Matzner, M. S. Mashuta and C. A. Grapperhaus, J. Am. Chem. Soc., 2015, 137, 9238-9241.

45 C. A. Downes, J. W. Yoo, N. N. Orchanian, R. Haiges and S. C. Marinescu, Chem. Commun., 2017, 53, 7306-7309.

46 K. Arai, T. Matsunaga, H. Ueno, N. Akahoshi, Y. Sato, G. Chakrabarty, G. Mugesh and M. Iwaoka, Chem.-Eur. J., 2019, 25, 12751-12760.

47 J. C. Pleasants, W. Guo and D. L. Rabenstein, J. Am. Chem. Soc., 1989, 17, 6554-6558.

48 H. J. Reich and R. J. Hondal, ACS Chem. Biol., 2016, 11, 821841. 